\title{
Pain Management at Inpatient Wards of a University Hospital
}

\author{
Sonia B. Felix Ribeiro ${ }^{1}$, João Carlos Pizani Pinto ${ }^{2}$, João Batista Ribeiro ${ }^{3}$, Márcia M. Santos Felix ${ }^{4}$, \\ Sabrina Martins Barroso ${ }^{5}$, Lucas Felix de Oliveira ${ }^{6}$, Andreza A. Felix ${ }^{7}$, Valdênia das Graças Nascimento ${ }^{8}$, \\ Matheus F. Felix Ribeiro ${ }^{9}$, Fátima A. Emm Faleiros Sousa ${ }^{10}$
}

Summary: Ribeiro SBF, Pinto JCP, Ribeiro JB, Felix MMS, Barroso SM, Oliveira LF, Felix AA, Nascimento VG, Ribeiro MFF, Sousa FAEF - Pain Management at Inpatient Wards of a University Hospital.

Background and objectives: This is an exploratory, descriptive and transversal study aiming to determine the prevalence, characterization, location, and measurement and discuss pharmacological analgesic measures for acute pain management in five inpatient wards of a university hospital.

Method: We enrolled 856 subjects in the study, of whom 272 were in pain at the time. Information related to pain was obtained using a bedside structured interview. Numeric pain scale and body diagram were used.

Results: Analgesia was assessed through medical records. The overall prevalence of pain was $31.8 \%$, with severe pain in $44.2 \%$ and mean of 6.6 on numeric pain scale. The main reason was trauma and the most common site the abdomen. The most widely used analgesic was dipyrone (76.1\%) with/without combination. Strong opioid was prescribed to $4.4 \%$. For $27.5 \%$ there was no improvement.

Conclusion: We conclude that pain is highly prevalent, poorly evaluated, undertreated, with inappropriate use of analgesics.

Keywords: Analgesia; Hospital Units; Pain measurement; Pain.

(C2012 Elsevier Editora Ltda. All rights reserved.

\section{INTRODUCTION}

Pain is understood as a multifactorial phenomenon, which comprises tissue injury and emotional, social, cultural, and environmental factors ${ }^{1}$, a definition that is consistent with the concept of pain expressed by the International Association for the Study of Pain (IASP) ${ }^{2-3}$. Pain is always subjective and each individual learns, feels, and uses this term from their previous experiences ${ }^{2}$.

Received from Universidade Federal do Triângulo Mineiro, Brazil.

1. Neurologist; Associate Professor of Neurology, Department of Internal Medicine, Pain Clinic, Universidade Federal do Triângulo Mineiro (UFTM)

2. MD; Neurology Resident, UFTM

3. Psychologist, MSc in Psychology, Professor of Psychology, UFTM

4. Nurse; MSc student, Health Sciences, Escola de Enfermagem de Ribeirão Preto, Universidade de São Paulo (USP)

5. Psycologist; MSc in Psychology; Professor of Psychology, UFTM

6. Psychologist; PhD Student of Health Sciences, Escola de Enfermagem de Ribeirão Preto, USP

7. Nurse; PhD Student, UFTM

8. MD; Specialist in Orthopaedics, UFTM; Fapemig

9. Psychologist; Universidade Federal de Minas Gerais

10. Full Professor, Department of General Nursing; Specialization, Escola de Enfermagem de Ribeirão Preto, USP

Submitted on October 22, 2011.

Approved on November 19, 2011

Correspondence to:

Sonia B. Felix Ribeiro, MD

Travessa Branca, 188

38057-060 - Uberaba, MG, Brazil

E-mail: ribeirofelix@terra.com.br
Acute pain acts as a warning signal or alarm, indicating the presence of toxic stimuli and/or tissue damage and is of fundamental importance to the physical integrity of individuals $^{3-4}$. The pain symptom is one of the main reasons for health care seeking in the general population ${ }^{5}$ and is very common in inpatient wards, especially in the emergency department as a result of trauma, inflammatory/infectious processes, burns, and ischemia, among others ${ }^{3}$. Pain control should be seen as a priority in the health care field ${ }^{5}$. Its relief may be understood as a basic human right, therefore, goes beyond the clinical issue to meet the ethical issue that involves health professionals ${ }^{5-6}$. Moreover, evidence shows that untreated pain may adversely affect the recovery process and tends to chronicity, which increases the social and financial costs involved ${ }^{6-7}$.

National 7,10-11 and international 8-9 studies indicate that acute or chronic pain is underdiagnosed, poorly evaluated, treated, and sometimes neglected at all levels of health care. Despite the relevance of pain symptom, there are few studies in Brazil on its prevalence in hospitalized patients, making it difficult to raise awareness of health professionals for the planning of actions, programs, and allocation of human and material resources in order to control inpatient pain.

In order to know the in-hospital pain management, a study was conducted with the following objectives: to determine the prevalence of acute pain in patients admitted to five inpatient wards of a university hospital; characterize and measure pain at the time of evaluation, and analyze the pharmacological analgesic measures adopted for these patients. 


\section{METHOD}

Cross-exploratory study approved by the Ethics Research Committee of a Federal University, under protocol 780/2006. The survey was conducted with patients admitted to the units of Internal Medicine, Surgical Clinic, Gynecology/Obstetrics, Neurology/Orthopedics, and Emergency Room (ER) of the Hospital de Clínicas, Universidade Federal do Triângulo Mineiro.

Individuals aged 15 years or more, of both sexes, regardless of ethnicity, admitted to one of the selected units, and able to communicate and understand the method of evaluation were enrolled in the study. All participants were informed about the study objectives, voluntarily agreed to cooperate, and signed the informed consent.

Data collection was conducted between May and June (2008) by a team previously trained on pain and interview techniques. The interviewers were residents of the university and students belonging to the League of Study and Support for the Patient with Pain, and supervised by a professor belonging to the Pain team.

Data were collected through structured interview, done at the bedside of the hospitalized patient. The patient was initially asked about the presence of pain at the time. If the patient was not in pain, the interviewer just thanked him and recorded the inpatient unit and bed number. If the patient was in pain, the interviewer proceeded with the questions set out in the research instrument. Demographic data (gender, age), skin color, and variables related to pain (cause, duration prior to hospitalization, location, frequency, intensity, characterization, reaction to pain etc.) were recorded. The interviews always occurred in the morning, and patients were followed until hospital discharge.

To assess the location and severity of pain, the Numerical Rating Scale (NRS) designed by Huskisson ${ }^{12}$ and body diagram (drawing of the human body in which the patient indicated the location of pain) were applied. The NRS scale ranges from zero (no pain) to ten points (worst possible pain), and the responses were categorized into four levels for this study, according to the WHO Analgesic Ladder ${ }^{13}$ : no pain (0), mild pain (1-3), moderate pain (4-7), and severe pain (8-10).

For analgesic pharmacology, medical records were consulted and annotated the analgesic requirements of the last 24 hours. The drugs were categorized into seven groups: Group 0 - no analgesic prescription; Group I - common analgesics; Group II - non-hormonal anti-inflammatory; Group III - weak opioid analgesics; Group IV - strong opioid analgesics; Group V - not informed; Group VI - other (drug compounds).

Data were analyzed using the software SPSS-PC for Windows. Initially, descriptive analysis was conducted to characterize the sample and pain reported by patients, in terms of mean and percentages. To investigate the relationship between inpatient wards, pain characteristics and analgesic prescriptions, Spearman correlation analysis, Kruskal-Wallis test of variance, and Bonferroni post hoc index were used ${ }^{14}$.

\section{RESULTS}

During the study period, 856 patients were hospitalized in one of the five selected units. The prevalence of pain assessed at the interview was $31.8 \%$, which means that 272 hospitalized patients experienced pain at some time during inward. The results presented below refer to patients with pain.

The age of patients ranged from 15 to 93 years, with a mean of 46.1 years $(S D=18.77)$. There was a predominance of white patients $(65.4 \%)$ and no gender prevalence $(50.4 \%$ women). Table I shows the distribution of hospitalized patients and presence or absence of pain.

The ER unit had more in-patients $(n=336)$. However, patients in Clinical Surgery (47.7\%) and Gynecology/Obstetrics $(42.7 \%)$ had the highest number of cases of pain. Table II shows the epidemiological characterization of patients with pain.

Patients who experienced pain were aged between 15 and 93 years, mean age of 46.09 years $(S D=18.77)$. As shown in Table II, $65.4 \%$ of patients with pain were mostly white (no sex prevalence). The characterization of pain reported by the patients is shown in Table III.

In Table III, it is observed that most patients experienced severe pain $(44.2 \%)$, representing 10 points in the numeric pain scale $(26.6 \%)$, and the mean pain intensity was 6.53 $(\mathrm{SD}=2.82)$. The duration of pain during pre-admission was between two and seven days for $29.4 \%$ of patients. The most

Table I - Distribution of Patients and Pain Cases by Inpatient Unit

\begin{tabular}{|c|c|c|c|c|c|c|}
\hline \multirow[t]{2}{*}{ Unit } & \multicolumn{2}{|c|}{$\begin{array}{l}\text { Total patients } \\
\text { seen }\end{array}$} & \multicolumn{2}{|c|}{$\begin{array}{l}\text { Patients with } \\
\text { pain }\end{array}$} & \multicolumn{2}{|c|}{$\begin{array}{l}\text { Patients } \\
\text { without pain }\end{array}$} \\
\hline & $\mathrm{N}$ & $\%$ & $\mathrm{~N}$ & $\%$ & $\mathrm{~N}$ & $\%$ \\
\hline ER & 336 & 39.2 & 116 & 34.5 & 220 & 65.5 \\
\hline Surgical Clinic & 111 & 13.0 & 53 & 47.7 & 58 & 52.3 \\
\hline Internal Medicine & 242 & 28.3 & 45 & 18.6 & 197 & 81.4 \\
\hline $\begin{array}{l}\text { Gynecology/ } \\
\text { Obstetrics }\end{array}$ & 89 & 10.4 & 38 & 42.7 & 51 & 57.3 \\
\hline $\begin{array}{l}\text { Neurology/ } \\
\text { Orthopedics }\end{array}$ & 78 & 9.1 & 20 & 25.6 & 58 & 74.4 \\
\hline Total & 856 & 100 & 272 & 31.8 & 584 & 68.2 \\
\hline
\end{tabular}

Table II - Characteristics of Patients with Pain Cared fort at the units of Hospital de Clínicas, Universidade Federal do Triângulo Mineiro

\begin{tabular}{lcclcc}
\hline Sex & $N$ & $\%$ & Ethnicity & N & $\%$ \\
\hline Female & 137 & 50.4 & White & 178 & 65.4 \\
Male & 135 & 49.6 & Black & 46 & 16.9 \\
& & & Brown & 18 & 17.6 \\
\hline
\end{tabular}

Revista Brasileira de Anestesiologia Vol. 62, № 5, September-October, 2012 
Table III - Pain Characteristics Reported by Patients

\begin{tabular}{|c|c|c|c|c|c|c|c|c|c|c|c|}
\hline $\begin{array}{l}\text { Severity of } \\
\text { pain }\end{array}$ & $\%$ & $\begin{array}{l}\text { Numerical } \\
\text { pain scale }\end{array}$ & $\%$ & $\begin{array}{l}\text { Duration of } \\
\text { pain prior to } \\
\text { hospitalization }\end{array}$ & $\%$ & Pain location & $\%$ & Cause of pain & $\%$ & Infection & $\%$ \\
\hline $\begin{array}{l}\text { Moderate } \\
(4 \text { a } 7)\end{array}$ & 38.0 & 2 & 3.7 & $2-5$ hours & 10.3 & Cervical & 1.8 & Neoplasia & 6.3 & No infection & 86.4 \\
\hline \multirow{7}{*}{$\begin{array}{l}\text { Severe } \\
(8 \text { a 10) }\end{array}$} & 44.2 & 3 & 11.1 & 6- 24 hours & 22.1 & Upper limbs & 9.0 & CVA & 2.2 & & \\
\hline & & & & & & & & & & & \\
\hline & & 4 & 11.1 & 2- 7 days & 29.4 & Chest & 12.7 & Headache & 8.8 & & \\
\hline & & 5 & 10.7 & $>1$ week & 19.1 & Abdominal & 21.5 & Vasculopathy & 4.0 & & \\
\hline & & 9 & 9.6 & & & $\begin{array}{l}\text { Anal, perineal, } \\
\text { and genital }\end{array}$ & 2.2 & $\mathrm{AMI}$ & 3.7 & & \\
\hline & & 10 & 26.6 & & & $\begin{array}{l}\text { More than three } \\
\text { sites }\end{array}$ & 1.8 & Other & 26.5 & & \\
\hline & & & & & & & & Not informed & 1.5 & & \\
\hline
\end{tabular}

frequent pain sites were the abdomen (23.5\%) and lower limbs (22.1\%). Most patients had no associated infections (86.4\%), and the main reason for pain was trauma (22.8\%), excluding the sum of causes included in the category "other causes of pain" (26.5\%). Table IV shows the analgesia approach, time to pain improvement after analgesia, and reactions of patients while in pain.

Most patients requested medication when in pain (46\%). However, analgesia was not administered to $53.7 \%$ of patients at the time pain was reported. The major route of analgesic administration was intravenous $(75.6 \%)$ and with fixed schedule $(57.7 \%)$, and dipyrone was the medication most commonly used $(75.7 \%)$. However, it is noteworthy that $21.3 \%$ of patients, even in pain, did not complain and $18.8 \%$ of patients complied with pain. For $22.4 \%$ of patients after analgesia, the pain lasted $2-10$ hours to improve and for $27.5 \%$ there was no improvement.

Correlations between variables are shown in Table $\mathrm{V}$. Complementation of correlation analysis was performed using the Kruskal-Wallis and Bonferroni post hoc tests and are described in the text.

\section{Correlations between pain characteristics and treatment received by inpatients}

Analyzes of variance and post hoc showed that patients treated at the Gynecology/Obstetrics unit had a lower mean age than patients treated at other units $(\mathrm{KW}=51.36, \mathrm{p}=0.000)$. In Internal Medicine wards, patients remained longer in pain, which also occurred in the ER $(\mathrm{KW}=27.26, \mathrm{p}=0.000)$. The Surgical Clinic was the unit that had a faster time to pain improvement $(\mathrm{KW}=14.71, \mathrm{p} \leq 0.05)$. While the greater intensity of pain occurred in patients treated at the $E R(K W=22.06$, $p=0.000)$.

There was also a correlation between the wards and the use of combined medications $(R=0.21, p \leq 0.001)$ and the pharmacological group used for analgesia $(R=0.23, p \leq 0.001)$ and the class of drugs associated $(R=0.24, p \leq 0.001)$. The post hoc analyzes indicated that the units of Internal Medicine and Gynecology/Obstetrics differ from the others and made less use of analgesic combination ( $K W=51.68, p=0.000)$.

Strong opioids were prescribed only in the ER unit, and Neurology/Orthopedics made predominant use of weak opioid analgesics $(\mathrm{KW}=22.01, \mathrm{p}=0.000)$. Patients treated with strong opioids improved in less than an hour and patients treated with weak opioids improved within one to two hours $(\mathrm{KW}=18.16, \mathrm{p}=0.000)$.

The age of patients was also significantly related with duration of pain $(R=0.27, p \leq 0.001)$ and reaction of patients with pain $(R=0.16, p \leq 0.05)$. The results indicated that the older the patient the longer the duration of pain. Post hoc analysis also showed that pain compliance was greater among patients between 80 and 82 years old $(K W=51.36, p \leq 0.001)$. Furthermore, the presence of infection increased duration of pain $(R=0.17, p \leq 0.001)$, and infection in the abdominal region and lower limbs showed the longest duration of pain $(\mathrm{KW}=17.55, \mathrm{p} \leq 0.05)$.

Intravenous analgesia showed significant correlation with faster relief of pain $(R=0.16, p \leq 0.05)$ and was mostly used 
Table IV - Characteristics of Analgesia Administered to Patient at the Units. Pharmacological Groups; Time Needed for Pain Improvement; Reaction of Patients with Pain

\begin{tabular}{|c|c|c|c|c|c|c|c|c|c|c|c|}
\hline 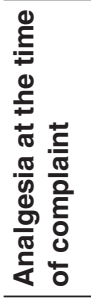 & ○ & 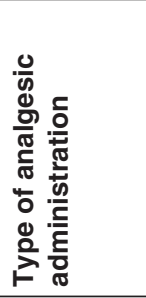 & ๑゚ & 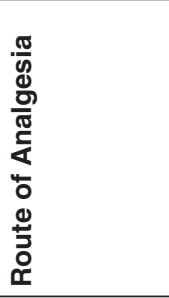 & ๑゚ & 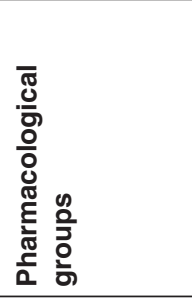 & $\circ$ & 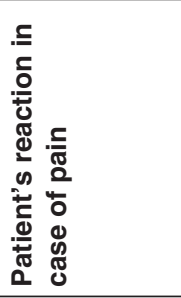 & ○ & 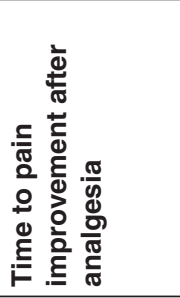 & ஃ \\
\hline Yes & 46.3 & $\begin{array}{l}\text { At the } \\
\text { discretion }\end{array}$ & 42.3 & Intravenous & 75.6 & Buscopan* & 2.6 & $\begin{array}{l}\text { Request } \\
\text { medication } \\
\text { (with/without } \\
\text { crying) }\end{array}$ & 46.0 & $<30 \mathrm{~min}$ & 19.5 \\
\hline \multirow[t]{12}{*}{ No } & 53.7 & Fixed time & 57.7 & Oral & 24.4 & Diclofenac** & 1.4 & Cry & 8.1 & $31 \mathrm{~min} .-1 \mathrm{~h}$ & 14.0 \\
\hline & & & & & & Morphine ${ }^{\star \star \star \star}$ & 2.6 & $\begin{array}{l}\text { Nervous/ } \\
\text { aggressive } \\
\text { (with/without } \\
\text { crying) }\end{array}$ & 4.0 & $1-2 \mathrm{~h}$ & 2.9 \\
\hline & & & & & & Dipyrone* & 75.7 & $\begin{array}{l}\text { Compliance } \\
\text { with pain }\end{array}$ & 18.8 & $2-10 h$ & 22.4 \\
\hline & & & & & & & & No complain & 21.3 & $11-24 \mathrm{~h}$ & 13.6 \\
\hline & & & & & & & & Other & 2.6 & $\begin{array}{l}\text { No } \\
\text { improvement }\end{array}$ & 27.5 \\
\hline & & & & & & Lisador* & 0.4 & & & & \\
\hline & & & & & & Neosaldina* & 0.4 & & & & \\
\hline & & & & & & Paracetamol $^{*}$ & 1.1 & & & & \\
\hline & & & & & & Ketoprofen ${ }^{\star *}$ & 0.4 & & & & \\
\hline & & & & & & 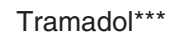 & 3.0 & & & & \\
\hline & & & & & & Codeine ${ }^{\star \star \star}$ & 0.4 & & & & \\
\hline & & & & & & Not informed & 11.4 & & & & \\
\hline
\end{tabular}

"Common analgesics; " "NSAIDs; "*"Weak opioids; " " "*Strong opioids.

Table V - Correlation between Pain Characteristics and Treatment Received by Inpatients at Units of the Hospital de Clínicas, Universidade Federal do Triângulo Mineiro

\begin{tabular}{|c|c|c|c|c|c|c|c|c|c|c|c|}
\hline & 売 & 冚 & 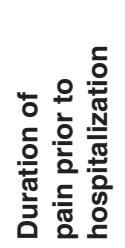 & 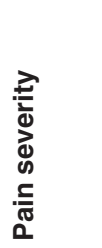 & 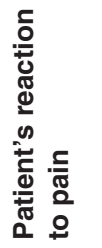 & 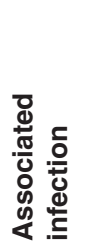 & 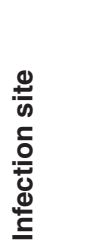 & 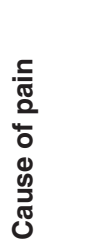 & 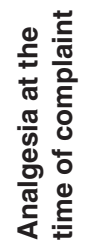 & 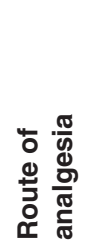 & 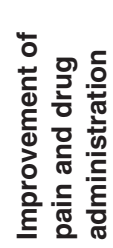 \\
\hline Unit & 1 & $0.18^{\star \star}$ & $0.15^{\star}$ & $0.27^{\star \star}$ & $0.18^{* *}$ & 0.03 & 0.05 & $0.39^{* *}$ & $0.21^{* \star}$ & $0.22^{\star \star}$ & $0.20^{\star \star}$ \\
\hline Age & $0.18^{*}$ & 1 & $0.27^{\star \star}$ & -0.01 & $0.16^{\star *}$ & 0.02 & 0.01 & 0.09 & 0.02 & 0.02 & 0.02 \\
\hline $\begin{array}{l}\text { Duration of pain prior to } \\
\text { hospitalization }\end{array}$ & $0.15^{\star}$ & $0.27^{\star *}$ & 1 & -0.06 & -0.04 & $-0.17^{\star}$ & $0.17^{\star *}$ & 0.07 & 0.00 & -1.09 & $0.26^{* *}$ \\
\hline Pain severity & $0.27^{* *}$ & -0.01 & -0.06 & 1 & 0.02 & -0.03 & -0.02 & $0.20^{* *}$ & 0.02 & -0.10 & $0.12^{*}$ \\
\hline Patient's reaction to pain & $0.18^{*}$ & $0.16^{*}$ & 0.04 & 0.02 & 1 & -0.04 & 0.01 & 0.01 & 0.11 & 0.01 & 0.07 \\
\hline Associated infection & 0.03 & 0.02 & $0.17^{\star \star}$ & -0.03 & -0.04 & 1 & $0.93^{* *}$ & -0.11 & -0.05 & 0.11 & 0.05 \\
\hline Infection site & 0.52 & 0.01 & $0.17^{* *}$ & -0.02 & -0.01 & $0.93^{* *}$ & 1 & -0.08 & -0.02 & $0.14^{*}$ & 0.04 \\
\hline Cause of pain & 0.39 ** & 0.09 & 0.07 & $0.20^{* *}$ & 0.01 & 0.11 & 0.08 & 1 & $0.17^{\star \star}$ & 0.11 & 0.08 \\
\hline $\begin{array}{l}\text { Analgesia at the time of } \\
\text { complaint }\end{array}$ & $0.21^{* *}$ & 0.02 & 0.00 & 0.02 & 0.11 & -0.05 & -0.02 & $0.17^{\star}$ & 1 & $0.16^{*}$ & $0.14^{*}$ \\
\hline Route of analgesia & $0.22^{* *}$ & 0.02 & 0.11 & -0.10 & 0.01 & 0.11 & $0.14^{*}$ & $0.11^{*}$ & $0.16^{\star *}$ & 1 & $-0.16^{*}$ \\
\hline Improvement of pain and drug & $0.20^{*}$ & 0.02 & $0.26^{*}$ & $0.12^{*}$ & 0.07 & 0.05 & 0.04 & 0.08 & $0.14^{*}$ & $-0.16^{*}$ & 1 \\
\hline
\end{tabular}

${ }^{* *} p \leq 0.001 ;{ }^{*} p \leq 0.05$ 
in patients with neoplasm and trauma, while the oral analgesia was most commonly used to treat headaches. The patients who received no analgesia at the time of complain improved within 2 to 10 hours after drug administration or not improved, even after receiving medication ( $K W=5.39, \mathrm{p} \leq 0.05)$.

\section{DISCUSSION}

Studying the prevalence of pain is an important indicator of quality care. Recent literature data has shown that over $50 \%$ of hospitalized patients complained of moderate to severe pain in the previous 24 hours, regardless of cause (surgical, neoplastic, traumatic, other) ${ }^{15-16}$. Some authors ${ }^{9,17}$ assessed pain at two times of hospital admission, during the interview and the previous 24 hours and found the prevalence of $23 \%$ $64 \%{ }^{9}$ and $38 \%-52 \%{ }^{17}$, respectively. In this study, we found an overall prevalence of $31.8 \%$ of pain during the interview (mean of 6.6 in NRS), with strong/severe pain in $44.2 \%$ of cases. In a study of prevalence of pain at 15 hospitals in Italy ${ }^{15}$, it was found that $46.6 \%$ of patients had severe pain, with mean intensity of seven points in NRS, data similar to this study.

Another aspect seen in this study is that, despite the apparent low prevalence of pain, if assessed by inpatient wards it is possible to observe that the prevalence was $47 \%$ in the Surgical Clinic and $42.7 \%$ in Gynecology/Obstetrics, a high rate in units related to surgical procedures. In a survey conducted in Recife ${ }^{18}$ on postoperative pain, it was found a $46 \%$ prevalence of pain in the first 24 hours, confirming the results found in this study, although the measurement of pain have been made at different times in each study and the present work does not necessarily have investigated patients undergoing surgical procedures.

Internal Medicine had the lowest prevalence of pain (18.6\%). This low prevalence may be because patients with acute pain, such as myocardial infarction and other acute abdominal and chest pain, remain in the ER unit until stabilization. The Internal Medicine unit serves older patients with respiratory complications, diabetes, malnutrition, decompensate heart disease, and cognitive decline who, perhaps by the evolution of their illness, are not aware or simply do not complain of pain. In a study ${ }^{8}$ of pain in elderly patients admitted to an Acute General Practice unit found a $70 \%$ prevalence of moderate intensity pain. The authors found that for half of reported cases there was no analgesic prescription and $37 \%$ of patients receiving analgesics, despite the persistence of pain, did not receive rescue medication. They concluded that the high prevalence of pain in the elderly highlights the need for guidelines and monitoring practices, as the elderly generally do not complain, even experiencing pain. Moreover, they reported that the elderly usually do not complain because they believe to be harassing the health professionals or because they have cognitive dysfunction. A similar phenomenon may have occurred in our study that has the same patients' profile. This could be a reason for the low prevalence of pain found in the Internal Medicine unit.
Other data that draw attention is that Internal Medicine was the unit administering more analgesics at the time of pain, but prescribed only if necessary. It was also the place in which patients experienced pain for a longer time and there was less use of analgesic combination. The most widely used analgesic was dipyrone for all types and degrees of pain. Moreover, the results indicate that age was correlated with pain. Older patients had longer duration of pain and, despite showing moderate to severe pain, their behavior was not to complain or to comply with it.

In Gynecology/Obstetrics there were pregnant women and patients with malignancies, situations in which pain is usually severe and analgesic measures should be systematic. Despite the high prevalence of pain $(42.7 \%)$, only common analgesics were prescribed, not opioids.

Although analgesic consumption is high in hospital settings, adherence to the World Health Organization (WHO) principles and recommendations regarding the use of analgesics in pain cases is still low. According to a study conducted in Italy ${ }^{15}$, this fact is due to lack of health professional's interest in pain management training. These authors concluded that only $8 \%$ of patients with pain were treated with opioids/NSAIDs combinations, which have synergistic interaction. In addition, only $6 \%$ used doses at fixed times and rescue doses, as recommended by the WHO for pain treatment in general ${ }^{15}$.

Despite the WHO considerations on the use of analgesics, concerns about the use of opioids seem to persist over the past decades ${ }^{19}$. Studies in France ${ }^{20-21}$ showed that $76 \%$ of physicians reported resistance in prescribing opioids for cancer pain. These studies confirmed the existence of behavioral barriers and lack of specific knowledge on the part of health professionals.

In a study on the use of opioids ${ }^{16}$, the authors compared the analgesic used in hospitalized patients with and without cancer. It was not possible to investigate the multiple causes of the undertreatment of pain by the results, but the authors believe that "opiofobia" - fear of using opioids associated with lack of knowledge about the appropriate management of analgesic drugs due to an overwhelming fear of abuse and dependence - would certainly be a factor, especially in cases of nonmalignant pain. They reported that another factor that could contribute to the low use of opioids would be the reluctance of patients and/or relatives to accept the use of these medications for fear of addiction. The authors concluded by saying that this results in inadequate dose administration, with no fixed dosage, especially when the causes of pain are nonmalignant.

There are few studies in Brazil on the use of opioids for pain treatment ${ }^{20,22}$. In a study of pain intensity and analgesic adequacy conducted at an emergency center ${ }^{7}$, the authors evaluated the use of analgesics in injuries from traffic accidents and found that in $36.9 \%$ of cases, despite serious injuries, dipyrone and paracetamol were the only analgesics prescribed. Dipyrone was also used in combination and the most prescribed analgesic (46.6\%). Weak opioids were used in $6.2 \%$, while morphine was used in $3.4 \%$ and meperidine in $10.4 \%$ of cases. 
Similarly, the results of this study indicate inadequate analgesic prescription and follow the same parameters of underutilized medication reported in the mentioned literature. The route of administration used was intravenous $(75.6 \%)$, and fixed time dose regimen was used only in $57.7 \%$ of cases. The most widely used analgesic was dipyrone $(76.1 \%$ of cases). Analgesics in combination were used in $50.7 \%$ of cases of pain and the most frequent combination was between common analgesics and weak opioids (22.4\%). Although the mean intensity of pain is moderate for most patients and considered unbearable in $26.6 \%$ (10 points on the NPS), strong opioids (morphine/meperidine) were prescribed for $4.4 \%$ of cases and only at the ER. Neurology/Orthopedics was the only unit prescribing predominantly analgesic combination, and the most common combination was between dipyrone and weak opioids.

There was also the combination of two weak opioids (tramadol and codeine) and between those and morphine, and $3.3 \%$ of patients with pain had not analgesic prescription.

The use of opioids in this study is consistent with reports of the International Narcotic Control Board (INCB) of the United Nations, which show evidence that in Brazil, morphine has been underutilized for pain treatment ${ }^{22}$ with subtherapeutic and non-fixed dose regimen.

Pain is a common and clinically relevant experience in hospital settings, but despite advances in understanding its mechanisms and treatment, research indicates that pain has not been recognized and treated appropriately in hospitalized patients. In this study, we found a prevalence of $31.8 \%$ of cas- es of pain detected during the interview, and $44.2 \%$ of these cases were considered severe pain (mean of 6.6 on NPS). Post-surgical recuperation and trauma were the main causes of pain. The most affected sites were the abdomen and lower limbs. The most severe pain occurred at the ER unit, where the use of analgesic combination was higher, including strong opioids. However, there was predominance in the use of analgesics at the discretion (if needed) and no administration at the time of pain. It was found that pain is poorly evaluated, undertreated, with the incorrect use of analgesics and underuse of opioids. Longer duration of pain prior to hospitalization was correlated with increased time required for improvement or no improvement of pain. Older patients had longer duration of pain and compliance with it. In order to improve pain, the intravenous administration of analgesics at the time of complaint was correlated with faster improvement.

The high prevalence of pain and lack of monitoring in different inpatient wards underscore the importance of implementing guidelines for managing pain in hospitals. This need was particularly important in units related to surgical procedures, which in this study were the unit with the highest prevalence of pain (47\%).

Hospitalization represents a delicate phase for patients and that moment can be aggravated by the unnecessary experience of pain. Awareness of health professionals to the importance of pain monitoring during hospital stay is of paramount importance and, in this sense, we expect that the information presented in this study may contribute to a broader discussion on the subject. 


\section{REFERENCES}

1. von Korff M, Dwokin SF, Le Resche L, Kruger A - An epidemiologic comparison of pain complaints. Pain, 1988;12:173-183.

2. Merskey NB - Classification of chronic pain: descriptions of chronic pain syndromes and definitions of pain terms prepared by the International Association for the Study of Pain. $2^{\text {nd }}$ ed. Seattle: IASP Press, 1994, pp. 240.

3. International Association for Study of Pain (IASP) - Consensus development conference statement: the integrated approach to the management of pain. J Accid Emerg Med, 1994;6(3):291-292.

4. Prado WA - Neurofisiologia e neuroquímica da dor aguda e crônica. In: Camargo AF. Dor: diagnóstico e tratamento. São Paulo: Roca; 2001, pp. 1-5.

5. Moura H - Direção-Geral da Saúde: Programa Nacional de Controle da Dor-Portugal (PNCDOR); 2008. Acessado em jan 2011. Disponível em: [http://www.aped-or.org/xFiles/scContentDeployer/docs/ Doc335.pdf].

6. Freitas CC, Vieira PR, Torres GB, Pereira CRA - Avaliação da dor com o uso das escalas unidimensionais. Rev Dor, 2009;10(1):56-62.

7. Calil AM, Pimenta CAM - Gravidade da lesão e analgesia em pacientes que sofreram acidente de transporte. Acta Paul Enferm, 2008;21(3):398-403.

8. Coker E, Papaioannou A, Turpie I et al. - Pain management practices with older adults on acute medical units. Perspectives, 2008;32(1):512.

9. Taylor EM, Boyer K, Campbell FA - Pain in hospitalized children: a prospective cross-sectional survey of pain prevalence, intensity, assessment and management in a Canadian pediatric teaching hospital. Pain Res Manay, 2008;13(1):25-32.

10. Calil AM, Pimenta CAM - Conceitos de enfermeiros e médicos de um serviço de emergência sobre dor e analgesia no trauma. Rev Esc Enferm USP, 2005;39(3):325-332.

11. Calil AM, Pimenta CAM - Intensidade da dor e adequação de analgesia. Rev. Latino-Am. Enfermagem, 2005;13(5):692-699.

12. Huskisson EC - Measurement of pain. Lancet, 1974;92(7889):11271131.

13. Organización Mundial de la Salud - Alivio del dolor y tratamiento paliativo en cáncer. Informe de un Comité de Expertos. Ginebra: OMS; 1990. (Serie de Informes Técnicos 804). Acessado em jan 2011. Disponível em: [http://www.whqlibdoc.who.int/publications/9243544829].

14. Soares JF, Siqueira AL - Introdução à estatística médica. Belo Horizonte: Coopmed, 2002, $2^{\text {a }}$ ed., pp. 300. 
15. Visentin M, Zanolin E, Trentin L, Sartori S, de Marco R - Prevalence and treatement of pain in adults admitted to Italian Hospitals. Eur $\mathrm{J}$ Pain, 2005;9:61-67.

16 Sichetti $\mathrm{D}$, Bandieri $\mathrm{E}$, Romero $\mathrm{M}$ et al. - Impact of setting of care on pain management in patients with câncer: a multicentre cross-sectional study. Annals Oncol, 2010;21(10):2088-2093.

17. Melotti RM, Samolsky-Dekel BGS, Ricchi E et al. - Pain prevalence and predictors among inpatients in a major Italian teaching hospital. A baseline survey towards a pain free hospital. Eur J Pain, 2005;9:485495.

18. Couceiro TCM, Valença MM, Lima LC, Menezes TC, Raposo MCF - Prevalência e influência do sexo, idade e tipo de operação na dor pós-operatória. Rev Bras Anestesiol, 2009;59(3):314-20.

19. Sommer M, Rijike JM, van Kleef M - The prevalence of postoperative pain in a sample of 1490 surgical inpatients. Eur J Anaesthesiol, 2008;25:267-274.

20. Larue F - Oncologists and primary care physicians - Attitudes toward pain control and morphine prescribing in France. Câncer, 1995;76(11):2375-2382.

21. Kipel AGB - Prevalência da dor: mitos, medos e desacertos relacionados ao uso de opiáceos. Texto Contexto Enferm, 2004;13(2):303308.

22. International Narcotic Control Board - L'utilisation des stupéfiants essentiels pour traiter la ouleur est insuffisante, en particulier dans les pays en développement. Relatório Anual 2004. Acessado em set 2010. Disponível em: [http://www.incb.org]. 